Short Communication openaccess Special Issue on Spectral Imaging in Synchrotron Light Facilities

\title{
Spatial distribution of starch, proteins and lipids in maize endosperm probed by scanning transmission $\mathrm{X}$-ray microscopy
}

\author{
Camille Rivard, ${ }^{\mathrm{a}, *}$ Benedicte Bakan, ${ }^{\mathrm{b}}$ Claire Boulogne, ${ }^{\mathrm{c}}$ Khalil Elmorjani, ${ }^{\mathrm{d}}$ Sufal Swaraj, ${ }^{\mathrm{e}}$ Rachid Belkhou ${ }^{\mathrm{f}}$ and \\ Didier Mariong,* \\ aDPT CEPIA, INRA, 44316 Nantes, France and Synchrotron SOLEIL, 91190 Gif-sur-Yvette, France. E-mail: camille.rivard@synchrotron-soleil.fr, \\ (1) https://orcid.org/0000-0001-5601-1989
}

${ }^{\mathrm{b} B I A}$, INRA, 44316 Nantes, France. (10 https://orcid.org/0000-0001-9088-1232

I2BC, CEA, CNRS, Univ. Paris-Sud, Univ. Paris-Saclay, 91198 Gif-sur-Yvette, France. 는tps://orcid.org/0000-0001-9633-9807

${ }^{\mathrm{d} B I A}$, INRA, 44316 Nantes, France

eSynchrotron SOLEIL, 91190 Gif-sur-Yvette, France. 는 https://orcid.org/0000-0001-7351-2320

fSynchrotron SOLEIL, 91190 Gif-sur-Yvette, France. ㄴ https://orcid.org/0000-0002-2218-7481

gBIA, INRA, 44316 Nantes, France. E-mail: didier.marion@inra.fr, (1) https://orcid.org/0000-0002-0672-6545

\begin{abstract}
The main storage components of the maize endosperm are starch, proteins and lipids. Starch and proteins are heterogeneously deposited, leading to the formation of vitreous and floury regions at the periphery and at the centre of the endosperm. The vitreous/floury mass ratio is a key physical parameter of maize end-uses for the food, feed and non-food sectors, as well as for the resistance of seeds to environmental aggressions. To improve maize breeding for vitreousness, one of the main issues is to finely delineate the molecular and physicochemical mechanisms associated with the formation of endosperm texture. In this context, we use scanning transmission X-ray microscopy at the C K-edge on maize endosperm resin-embedded ultrathin sections. The combination of local near edge X-ray absorption fine structure (NEXAFS) spectroscopy and high-resolution images enable us to achieve a quantitative fine description of the spatial distribution of the main components within the endosperm.
\end{abstract}

Keywords: carbon, lipid, starch granule, protein, soft X-ray imaging and spectroscopy, STXM

\section{Introduction}

The multiple end-uses of maize crops are, in part, based on the assembly of the main storage components of the endosperm, i.e. starch and proteins (zeins). Indeed, starch and proteins are heterogeneously deposited leading to the formation of vitreous (endosperm periphery) and floury regions (endosperm centre). Vitreousness determines the food and feed quality of maize and is also important for the resistance of seeds to environmental biotic and abiotic stresses. ${ }^{1}$ The molecular and physicochemical basis of maize endosperm vitreousness was recently investigated
Correspondence

Camille Rivard (camille.rivard@synchrotron-soleil.fr) and Didier Marion (didier.marion@inra.fr)

Received: 13 March 2019

Revised: 20 October 2019

Accepted: 4 November 2019

Publication: 13 November 2019

doi: 10.1255/jsi.2019.a21

ISSN: $2040-4565$

\begin{abstract}
Citation
C. Rivard, B. Bakan, C. Boulogne, K. Elmorjani, S. Swaraj, R. Belkhou and D. Marion, "Spatial distribution of starch, proteins and lipids in maize endosperm probed by scanning transmission X-ray microscopy", J. Spectral Imaging 8, a21 (2019). https://doi.org/10.1255/jsi.2019.a21

(c) 2019 The Authors

This licence permits you to use, share, copy and redistribute the paper in any medium or any format provided that a full citation to the original paper in this journal is given, the use is not for commercial purposes and the paper is not changed in any way.
\end{abstract}


for commercial inbred lines. ${ }^{2-4}$ Using Raman microspectrometry ${ }^{3}$ and matrix-assisted laser desorption/ionisation (MALDI) mass spectrometry imaging, ${ }^{4}$ it was shown that vitreousness follows the gradient from the periphery to the centre of the endosperm that is related to starch, protein and lipid gradients. Indeed, starch content and crystallinity increase from the periphery to the centre of the endosperm, while the protein content is higher at the periphery than in the centre. Starch crystallinity gradients are well related to changes in the amylose and amylopectin (the linear and branched carbohydrate polymers of starch granules, respectively) mass ratio, and to changes in contents and composition of lipids embedded in starch granules. These starch-bound lipids are composed of free fatty acids and lysophosphatidylcholine (lysoPC) that are complexed with amylose helices. ${ }^{5}$ By MALDI imaging we also observed a gradient of lysoPC from the periphery to the endosperm centre. ${ }^{4}$ These results obtained by different techniques suggest that the distribution of carbon (C) between starch polysaccharides, proteins and lipids controls the packing of the endosperm starch-protein matrix and, therefore, are closely related to the endosperm vitreousness. However, any of the techniques used in these studies could highlight the spatial distribution of the key components at a high spatial resolution.

C K-edge near edge $\mathrm{X}$-ray absorption fine structure (NEXAFS) spectromicroscopy on a scanning transmission X-ray microscope is well suited to the study of the carbonated molecules with a spatial resolution down to $30 \mathrm{~nm}$ and without any labelling agents. This technique has been used in biology for the characterisation of proteins and DNA in chromosomes, ${ }^{6-8}$ in wood and lignified plants,, 910 in modern and fossil sporoderms, ${ }^{11}$ and in bones and teeth. ${ }^{12}$ Some studies were dedicated to $C$ characterisation in cells or soft tissues, such as the mapping of the matrix of microbial biofilms and standard lipid proteins, ${ }^{13}$ the mapping of C. crescentus cells, ${ }^{14}$ the modification of polysaccharides in vascular plant cell walls, ${ }^{15}$ the mapping of vascular smooth muscle cells, ${ }^{16}$ the determination and location of plant biopolymers in lentils and wheat grain ${ }^{17}$ or the mapping of proteins in amyloid plaques correlated with Alzheimer's disease. ${ }^{18}$

In the present communication we use scanning transmission X-ray microscopy (STXM) at the C K-edge to determine the spatial distribution of the three main components of maize endosperm to better understand the heterogeneity of endosperm composition.

\section{Material and methods Sample preparation}

Maize grains were supplied by Limagrain Europe (SaintBeauzire, France) and reference samples were purified by the INRA-BIA laboratory (Nantes, France) from these maize grains (lipids) or from commercial products (starch and proteins) according to the procedure described in References 3, 4 and 19. Zeins, the main maize endosperm proteins representing about $80 \%$ of the total proteins, were used as reference proteins. Crude zeins (Sigma-Aldrich, France) were solubilised in ethanol $70 \%$ in water and precipitated with acetone at $-20^{\circ} \mathrm{C}$. After centrifugation at $8000 \mathrm{~g}$ the zein sediment was dispersed in deionised water and freeze-dried. Crude starch (Sigma-Aldrich, France) was washed for $1 \mathrm{~h}$ with $70 \%$ ethanol, then twice with deionised water and freeze-dried. Starch was cryo-ground after extraction in order to obtain enough thin fragments for $X$-ray transmission measurements. Lipids were extracted from endosperm flour with 2-propanol and chloroformmethanol 2:1 ( $\mathrm{v}: \mathrm{v})$ and finally purified by phase partitioning in chloroform-methanol- $\mathrm{NaCl} 1 \%$ as previously described. ${ }^{4}$ After drying, maize lipids were fractionated on a silica solid phase extraction cartridge $(500 \mathrm{mg}$, SupelClean LC-Si, Supelco, USA) by eluting successively the column with chloroform-acetic acid 1\% (non-polar lipids), acetone (glycolipids) and methanol (phospholipids). ${ }^{4}$ Each lipid fraction is a mixture of different molecules sharing structure similarities. For example, glycolipids are mainly composed of galactosyldiacylglycerol, non-polar lipids are composed of triacylglycerols and phospholipids of phosphatidylcholine. ${ }^{4}$ Nevertheless, in each fraction, the proportion of the different molecules reflects the proportion of these molecules in the corresponding maize endosperms. Starch lipids were extracted from the freeze-dried maize starch with hot $80 \%$ 1-propanol in water and purified by phase partitioning in chloroform-methanol- $\mathrm{NaCl} 1 \%$. These lipids are mainly composed of free fatty acids and lysophosphatidylcholine. ${ }^{4}$ The reference samples were dissolved or dispersed in appropriate solvent (water, ethanol or chloroform, as a function of the reference), adapting the concentration for each reference to obtain a thin and homogeneous deposit after droplet deposition onto a $\mathrm{Si}_{3} \mathrm{~N}_{4}$ window $(50 \mathrm{~nm}$ thicknesses, $0.5 \times 0.5 \mathrm{~mm}^{2}$ area, Norcada Inc., Edmonton, Canada) and air-dried. Ultrathin sections of maize grains on grids were prepared at Imagerie Gif platform following the protocol described in Table 1.

The grids and the $\mathrm{Si}_{3} \mathrm{~N}_{4}$ windows were mounted on the sample holder of the scanning transmission $\mathrm{X}$-ray micro- 
Table 1. Steps, chemical products and equipment used for ultrathin sections preparation.

\begin{tabular}{|c|c|}
\hline Step & Chemical products and equipment \\
\hline $\begin{array}{l}\text { Cylinder volume ( } 1.2 \mathrm{~mm} \text { in diameter, } \\
400 \mu \mathrm{m} \text { in height) extraction from } \\
\text { maize grain endosperm }\end{array}$ & $\begin{array}{l}\text { VT1200S vibratome, Leica Microsystems } \\
\text { Whatman WB100028 punch Uni-Core } \\
400 \text { um-flat specimen carriers } 16706899 \text {, Leica Microsystems }\end{array}$ \\
\hline High pressure freezing & $\begin{array}{l}\text { EM PACT2, Leica Microsystems } \\
\text { using Dextran cryoprotectant, 31389, Sigma } \\
\text { or without Dextran }\end{array}$ \\
\hline Cryo-substitution & $\begin{array}{l}\text { EM AFS2 and FSP, Leica Microsystems } \\
\text { using HM20 acrylate resin, 14345, EMS } \\
\text { or using glycidyl methacrylate resin, 868-77-9, Spi CHEM }\end{array}$ \\
\hline Resin polymerisation & $\begin{array}{l}-45^{\circ} \mathrm{C} \text { for } 48 \mathrm{~h} \text { then } 0^{\circ} \mathrm{C} \text { for } 28 \mathrm{~h} \text { under ultraviolet light for } \mathrm{HM} 2 \mathrm{O} \\
-30^{\circ} \mathrm{C} \text { during } 24 \mathrm{~h} \text { using } 15 \mathrm{\mu L} \text { of } \mathrm{N}, \mathrm{N} \text {-dimethyl-p-toluidine, Merck } \\
8.22040 .0005 \text { for } 5 \mathrm{~mL} \text { of resin, for GMA }\end{array}$ \\
\hline $100 \mathrm{~nm}$ thick ultrathin sectioning & Ultramicrotome UC6, Leica Microsystems \\
\hline Ultrathin sections deposition on grids & Uncoated Cu grids, G2375C, Agar Scientific \\
\hline
\end{tabular}

scope and pre-screened using an optical microscope to select the areas of interest. The sample holder was then placed in the experimental scanning transmission $\mathrm{X}$-ray microscope chamber and pumped down to $10^{-2} \mathrm{mbar}$.

\section{K-edge NEXAFS spectra collection}

The micro-spectroscopic data were collected on the scanning transmission $\mathrm{X}$-ray microscope end-station of the HERMES beamline (SOLEIL synchrotron), a particularly well-adapted beamline for carbon K-edge investigations. ${ }^{20,21}$ The $X$-ray beam was focused to $38 \mathrm{~nm}$ using a $30 \mathrm{~nm}$ Fresnel zone plate and the transmission signal was collected using a photomultiplier tube. The $\mathrm{C} 1 \mathrm{~s} \rightarrow \pi^{*}$ transition in the NEXAFS spectra of a PC71BM sample ${ }^{22}$ at $284.43 \mathrm{eV}$ was used for energy calibration. The stacks of images were collected on fields of view from $8 \mu \mathrm{m}$ to $15 \mu \mathrm{m}$ large, scanning the sample with $50 \mathrm{~nm}$ steps in both horizontal and vertical directions at each energy increment over the energy range of $\mathrm{C}$ K-edge. Each stack was composed of 165 images, covering the energy range between $270 \mathrm{eV}$ and $350 \mathrm{eV}$, with a sampling step set of $1 \mathrm{eV}$ from $270 \mathrm{eV}$ to $280 \mathrm{eV}, 0.2 \mathrm{eV}$ from $280 \mathrm{eV}$ to $283 \mathrm{eV}$, $0.08 \mathrm{eV}$ from $283 \mathrm{eV}$ to $290 \mathrm{eV}$ (the edge region) and $1.2 \mathrm{eV}$ from $290 \mathrm{eV}$ to $350 \mathrm{eV}$.

\section{K-edge NEXAFS data analyses}

The stack of images was analysed using aXis2000 (http:// unicorn.mcmaster.ca/aXis2000.html) ${ }^{23}$ and Mantis (http://spectromicroscopy.com) $)^{24}$ software. The images were aligned using the alignment routine of the Stack
Analyze program (Jacobsen/Stony Brook). The transmission images were then converted into optical density (OD) scales according to the following equation: $O D=-\operatorname{In}(/ /$ $\left.I_{0}\right)=\sigma t=\mu \rho t$, where $I_{0}$ represents the incident $X$-ray flux measured on a free area of the sample holder, I represents the measured transmitted intensity at the pixel of interest, $\sigma$ is the linear absorption coefficient, $t$ is the thickness, $\mu$ is the mass absorption coefficient and $\rho$ is the density. An image taken before the edge is considered as background and subtracted from the others. Principal component analysis (PCA) was applied on stacks of images using Mantis software and the number of principal components (PC) was determined based on the recommendations for STXM analyses. ${ }^{25}$ Cluster analyses (CA) and non-negative matrix approximation (NNMA) routines were conducted using Mantis default settings and using the PC number previously determined. For NNMA, the initial spectra were the cluster spectra found in the CA. Quantitative component images were produced using the singular value decomposition linear regression procedure with starch, zeins and lipids as reference spectra. RGB images were plotted using Fiji software. ${ }^{26}$

\section{Results and discussion \\ References spectra}

The C K-edge NEXAFS spectra collected on purified references evidence specific features useful to discriminate the three main components of maize endosperm, i.e. 


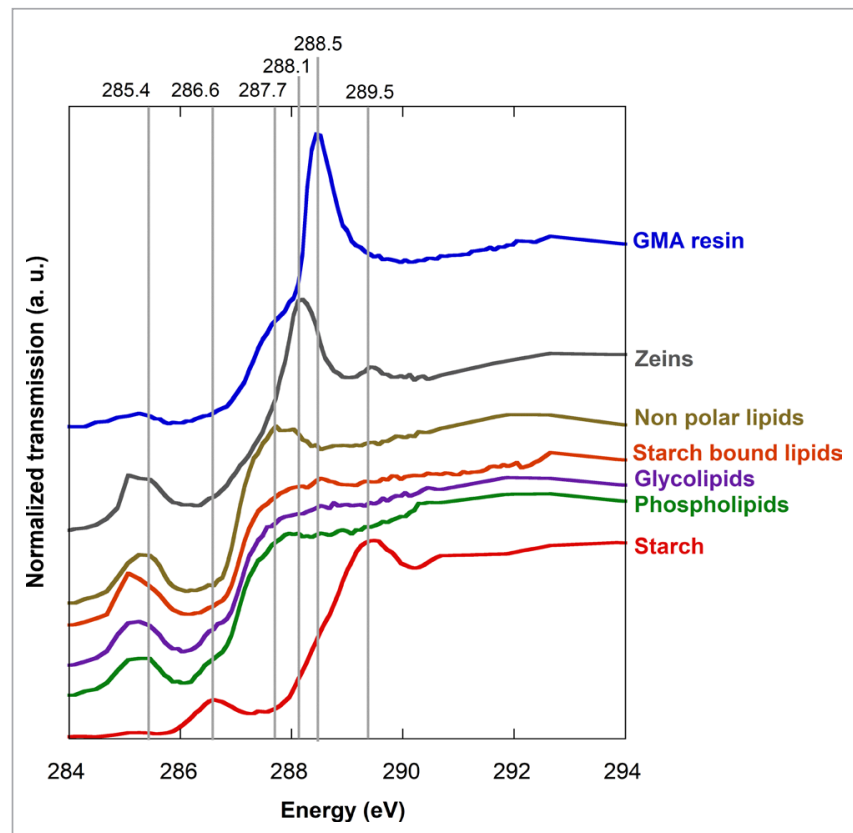

Figure 1. C K-edge NEXAFS spectra of the set of references and of the resin. For clarity the spectra were shifted vertically to avoid superimposition. Grey lines corresponding to the energies of the single energy images in Figure 2.

starch, proteins (zeins) and lipids (Figure 1). The starch spectrum displays a broad white line centred on $289.5 \mathrm{eV}$ and a pre-edge at $286.6 \mathrm{eV}$. These features are in agreement with the published spectrum of wheat starch. ${ }^{17}$ The edge of the zein spectrum is shifted towards lower ener- gies in comparison to starch, with an intensive feature at $288.1 \mathrm{eV}$ corresponding to the amide carbonyl group (peptide bond in proteins). In the post-edge region of the zeins spectrum, a peak occurs at $289.5 \mathrm{eV}$, as observed in the albumin spectrum. ${ }^{13,18}$ The edge position of the three types of lipids display similar positions (around $287 \mathrm{eV}$ ) and are even more shifted toward lower energies in comparison to starch and zein edge spectra. The large pre-edges of lipids between $284.9 \mathrm{eV}$ and $285.5 \mathrm{eV}$ are superimposed on the zein pre-edge. The non-polar lipids display a broad white line at $287.7 \mathrm{eV}$, whereas the other analysed lipids do not evidence this pronounced peak. The GMA resin evidenced a white line at $288.5 \mathrm{eV}$ with a pre-edge shoulder around $287.7 \mathrm{eV}$.

\section{Effect of resin on spectrum acquisition}

Studies of plant tissues at the C K-edge, and thus the protocols of preparation of plant tissues have been poorly documented in the literature. Our samples were prepared using two types of resins and with or without Dextran, a cryo-protectant commonly used for the preparation of transmission electron microscopy samples during cryo-plunge to reduce crystallisation and better preserve the samples' structures. The energy stack recorded on samples embedded in the $\mathrm{HM} 20$ resin evidenced radiation damage due to carbon deposition on the surface area of samples and leading to the visual blackening of the surface area and to a flattening of the $\mathrm{C}$

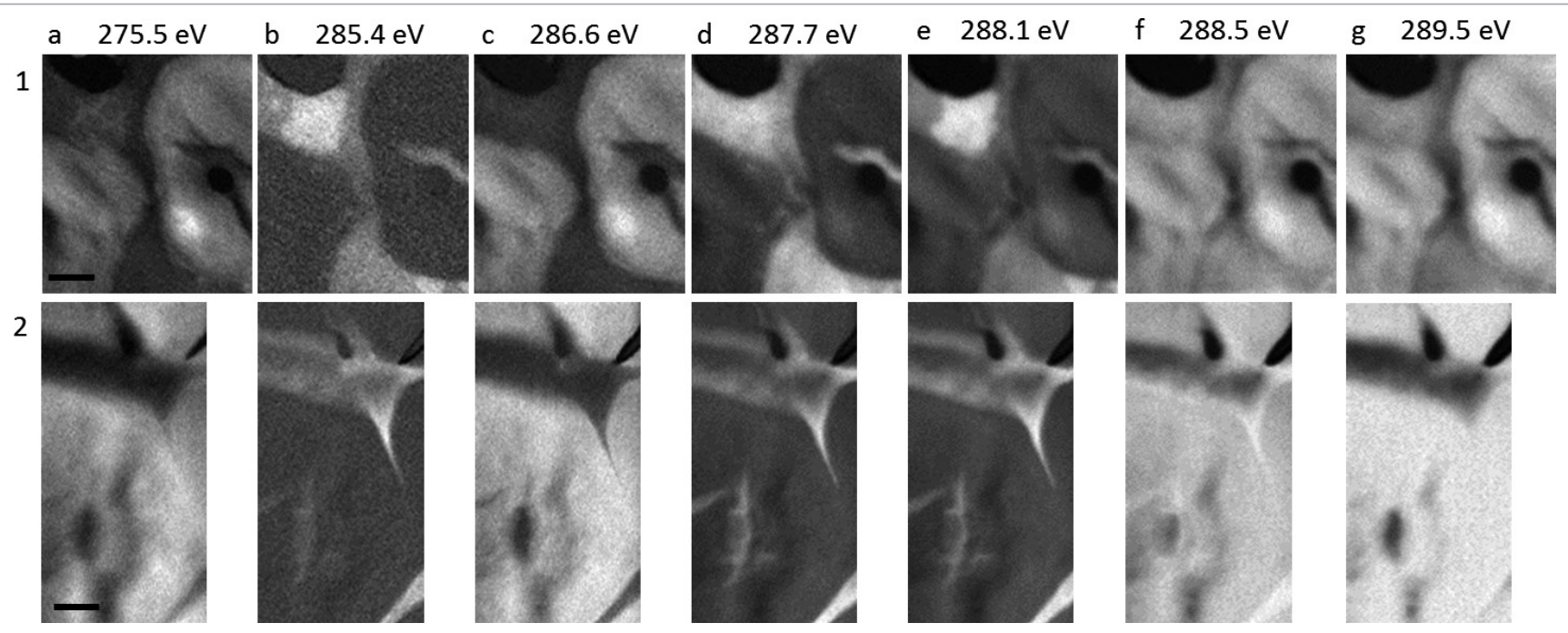

Figure 2. OD STXM images at the $C$ K-edge of two parts of the maize endosperm (stacks 1 and 2) of a: before the edge (275.5 eV); b: lipids-zeins pre-edge $(285.4 \mathrm{eV})$; c: starch pre-edge $(286.6 \mathrm{eV})$; d: lipids white line $(287.7 \mathrm{eV})$; e: zeins white line $(288.1 \mathrm{eV})$; f: resin white line $(288.5 \mathrm{eV})$; and g: starch white line $(289.5 \mathrm{eV})$. White and black areas correspond to high and low X-ray absorption, respectively. Scale bar is $2 \mu \mathrm{m}$. 


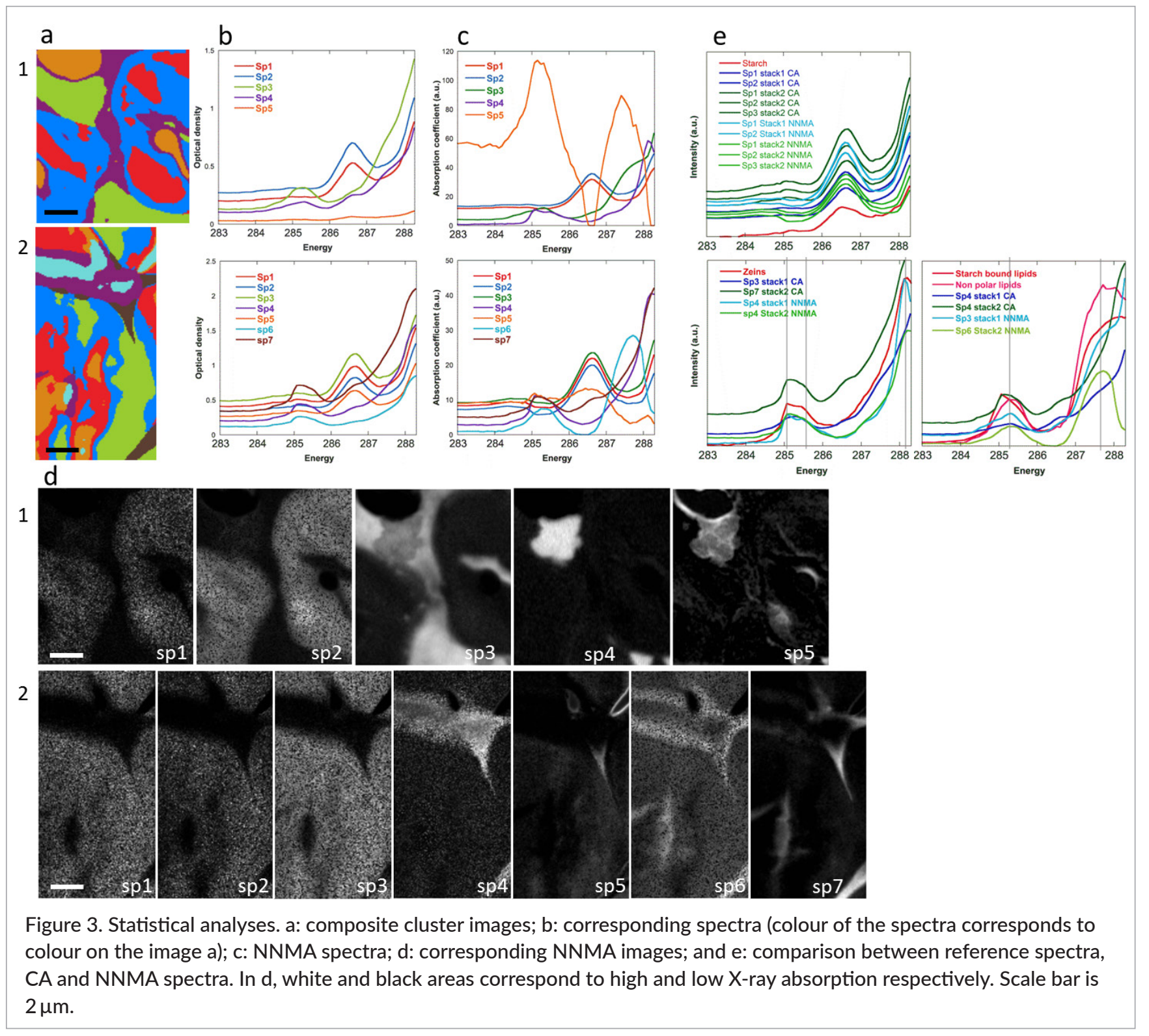

K-edge spectra (not shown). This radiation damage effect is enhanced by the use of Dextran. By contrast, no such effects have been observed on the samples embedded in the GMA resin without Dextran. The results presented hereafter were obtained with the latter sample preparation procedure.

\section{Stack analyses}

The single energy images extracted from the stacks show the contrast resulting from the $\mathrm{C}$ composition heterogeneity of the sample (Figure 2). The white areas on Figure 2c, d and e evidence the location of starch, lipids and zeins, respectively. Figure 2b, recorded at $285.4 \mathrm{eV}$ corresponds to a combination of lipids and zeins distribu- tions (the image appears as a combination of the images of Figure $2 \mathrm{~d}$ and $\mathrm{e}$ ), the pre-edges of these two species being at the same energy position (Figure 1). Figure $2 f$, corresponding to the resin intensive feature energy, shows a relatively low contrast in the image resulting from the contribution of almost all the constituents of the preparation, including resin, except for the two holes which appear totally black. Figure $2 \mathrm{~g}$ is supposed to correspond to the starch distribution, but at this energy all the species, including resin, contribute to the starch signal scrambling.

To limit artefacts resulting from the presence of the resin, PCA, CA and NNMA analyses were conducted on the stacks of images in the energy range from $283.6 \mathrm{eV}$ 
to $288.3 \mathrm{eV}$ (cutting just after the zein white line) only. Five and seven PCs were obtained by PCA analyses for stack 1 and 2, respectively. Among the spectra obtained with CA, only three types of spectra describe all the voxels of the stack of images, holes excluded (sp5 in stack 1) as sp1 and 2 for stack 1, sp1, 2, 3 and 5 for stack 2 and sp 4 and 6 for stack 2 are considered as the same shape, the variation only comes from a slight variation of intensity (Figure $3 a$ and b). As for CA, some spectra obtained using NNMA routines can be considered as similar; the resulting components images stack $1 \mathrm{sp} 1$ and sp2 and stack 2 sp1, sp2 and sp3, describe the same area (Figure $3 \mathrm{~d}$ ) and correspond to the spatial distribution of starch (Figure 3e). The sp4 stack 1 components image evidences specific features not visible on CA images such as the white patch visible on Figure 2e, stack 1. The corresponding spectra sp4 shows a large double peak between $285 \mathrm{eV}$ and $286 \mathrm{eV}$ and a sharp peak at $288.1 \mathrm{eV}$. These features are characteristic of zeins reference spectra (Figure 1 and 3e).

Figure 4 shows components images of each of the spectral reference components (starch, zeins, nonpolar lipids and starch bound lipids) and the resulting RGB composite images. As expected, starch appears only localised in the large spherical grains (Figure 4a). Zeins are localised in well-defined round globules (Figure 4b, stack 1) or distributed in all the interstarch grain space as a function of the area of the endosperm investigated (Figure 4b, stack 2). Non-polar lipids are mainly detected in the inter-starch grains space with more or less abundance as a function of the area of the endosperm. They are also detected in the centre of the starch grains (Figure 4c). The starch grains do not appear totally lacking in lipids (Figure 4c) and interestingly, when fitting the stack of images using starch bound lipids (Figure 4f), significantly higher amounts of starch bound lipids are detected co-localised with starch in comparison to fitting with polar lipids. Moreover, the different nuances of the red and of the violet of the starch grains in the RGB images (Figure $4 d$ and $f$, respectively) between the two stacks of the endosperm clearly evidence a difference of composition with a higher starch/lipids ratio for stack 1 than for stack 2. All the features evidenced though CA and NNMA images were also observed in these distribution maps, validating our assumption that our selected references are able to describe all the features observed in the $\mathrm{C} \mathrm{K}$-edge spectra.

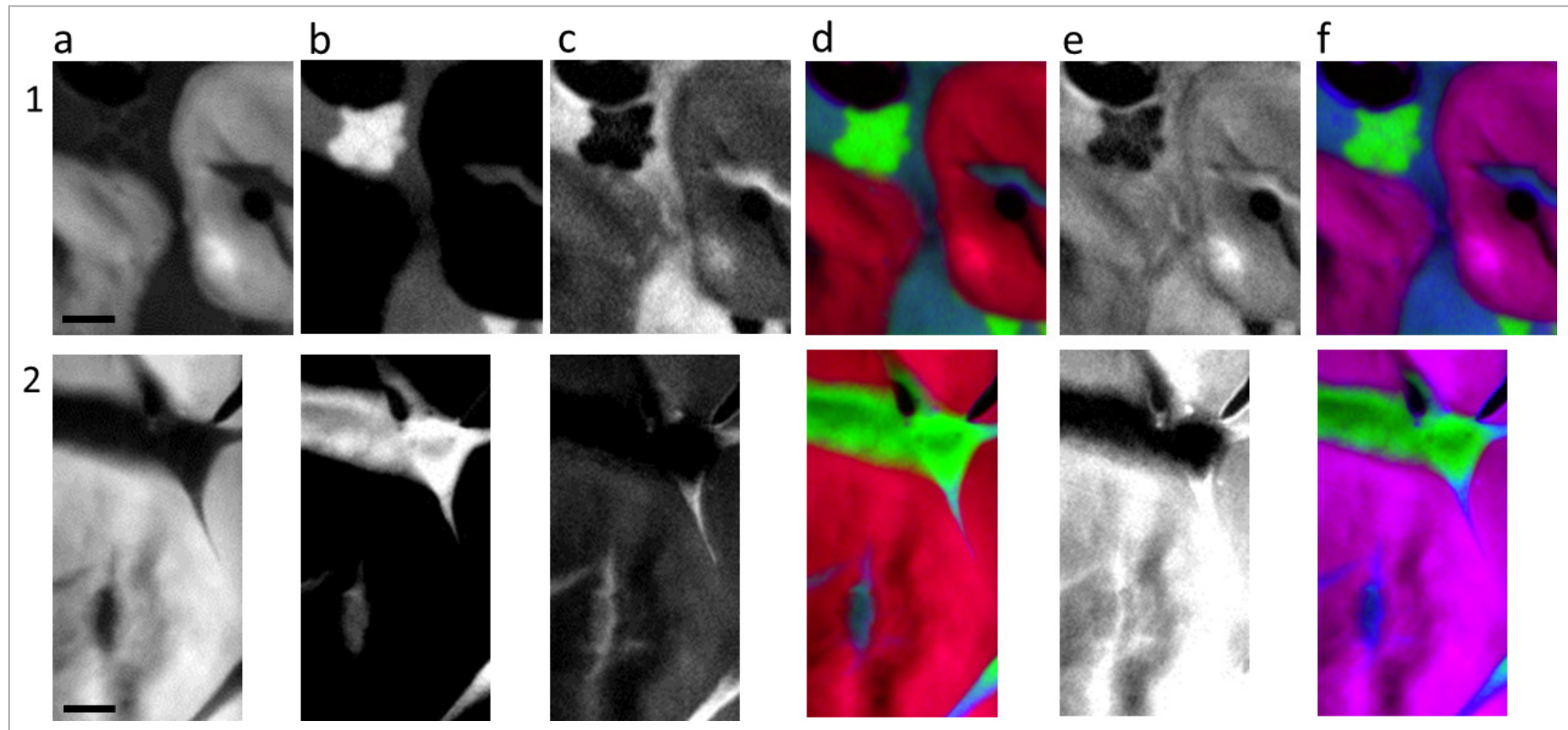

Figure 4. Components images of two parts of the maize endosperm (stacks 1 and 2). a: starch; b: zeins; c: non-polar lipids; d: RGB starch (red), zeins (green), non-polar lipids (blue) images; e: starch bound lipid; and f: RGB starch (red), zeins (green), starch bound lipids (blue) image. Scale bar is $2 \mu \mathrm{m}$. For a to $\mathrm{c}$ and e, white and black areas correspond to high and low abundance, respectively. Intensity grey scale is similar for both parts for each molecule. Colour scale is similar for both parts for each molecule. 


\section{Conclusion}

These investigations strongly confirm the feasibility of discriminating the three main components in maize endosperm using C K-edge STXM spectromicroscopy, even on resin-impregnated samples and without any staining. As the samples were prepared and analysed under identical conditions, the proportions of the component obtained in the components images of several samples can be directly quantitatively compared. The spectral images with $38 \mathrm{~nm}$ spatial resolution make it possible to discriminate, locate and quantify starch, zeins and lipids as well as the different types of lipids. The next step of this work is to analyse several areas in the vitreous and floury parts in endosperm to be able to quantify, with statistical information, the evolution in terms of main components and distribution to better understand the evolution in between vitreous and floury parts.

\section{Acknowledgements}

The authors would like to thank Frédéric Jamme and Pierre Legrand for their encouragement in exploring soft X-ray capabilities for biological samples. We acknowledge SOLEIL for provision of synchrotron radiation facilities through the proposal 20161149.

\section{References}

1. S. Tamagno, I.A. Greco, H. Almeida and L. Borrás, "Physiological differences in yield related traits between flint and dent Argentinean commercial maize genotypes", Eur. J. Agron. 68, 50 (2015). https://doi.org/10.1016/j.eja.2015.04.001

2. M. Gayral, B. Bakan, M. Dalgalarrondo, K. Elmorjani, C. Delluc, S. Brunet, L. Linossier, M.-H. Morel and D. Marion, "Lipid partitioning in maize (Zea mays L.) endosperm highlights relationships among starch lipids, amylose, and vitreousness", J. Agric. Food Chem. 63(13), 3551 (2015). https://doi.org/10.1021/ acs.jafc. $5 b 00293$

3. M. Gayral, C. Gaillard, B. Bakan, M. Dalgalarrondo, K. Elmorjani, C. Delluc, S. Brunet, L. Linossier, M.-H. Morel and D. Marion, "Transition from vitreous to floury endosperm in maize (Zea mays L.) kernels is related to protein and starch gradients", J. Cereal
Sci. 68, 148 (2016). https://doi.org/10.1016/j. jcs.2016.01.013

4. M. Gayral, M. Fanuel, H. Rogniaux, M. Dalgalarrondo, K. Elmorjani, B. Bakan and D. Marion, "The spatiotemporal deposition of Iysophosphatidylcholine within starch granules of maize endosperm and its relationships to the expression of genes involved in endoplasmic reticulum-amyloplast lipid trafficking and galactolipid synthesis", Plant Cell Physiol. 60(1), 139 (2019). https://doi.org/10.1093/pcp/pcy198

5. S. Pérez and E. Bertoft, "The molecular structures of starch components and their contribution to the architecture of starch granules: a comprehensive review", Starch - Stärke 62(8), 389 (2010). https://doi. org/10.1002/star.201000013

6. S. Williams, X. Zhang, C. Jacobsen, J. Kirz, S. Lindaas, J.V. Hof and S.S. Lamm, "Measurements of wet metaphase chromosomes in the scanning transmission X-ray microscope", J. Microsc. 170(2), 155 (1993). https://doi.org/10.1111/j.1365-2818.1993. tb03335.x

7. H. Ade, X. Zhang, S. Cameron, C. Costello, J. Kirz and S. Williams, "Chemical contrast in X-ray microscopy and spatially resolved XANES spectroscopy of organic specimens", Science 258(5084), 972 (1992). https://doi.org/10.1126/science.1439809

8. Z. Yangquanwei, S. Neethirajan and C. Karunakaran, "Cytogenetic analysis of quinoa chromosomes using nanoscale imaging and spectroscopy techniques", Nanoscale Res. Lett. 8(1), 463 (2013). https://doi. org/10.1186/1556-276X-8-463

9. G.D. Cody, "Probing chemistry within the membrane structure of wood with soft X-ray spectral microscopy", in AIP Conference Proceedings 507, 307 (2000). https://doi.org/10.1063/1.1291162

10. C.K. Boyce, G.D. Cody, M.L. Fogel, R.M. Hazen, C.M.O. Alexander and A.H. Knoll, "Chemical evidence for cell wall lignification and the evolution of tracheids in early Devonian plants", Int. J. Plant Sci. 164(5), 691 (2003). https://doi.org/10.1086/377113

11. S. Bernard, K. Benzerara, O. Beyssac, G.E. Brown, L.G. Stamm and P. Duringer, "Ultrastructural and chemical study of modern and fossil sporoderms by scanning transmission X-ray microscopy (STXM)", Rev. Palaeobot. Palynol. 156(1), 248 (2009). https:// doi.org/10.1016/j.revpalbo.2008.09.002

12. J. Cosmidis, K. Benzerara, N. Nassif, T. Tyliszczak and F. Bourdelle, "Characterization of Ca-phosphate 
biological materials by scanning transmission $X$-ray microscopy (STXM) at the Ca L2,3-, P L2,3- and C K-edges", Acta Biomater. 12, 260 (2015). https://doi. org/10.1016/j.actbio.2014.10.003

13. J.R. Lawrence, G.D.W. Swerhone, G.G. Leppard, T. Araki, X. Zhang, M.M. West and A.P. Hitchcock, "Scanning transmission $\mathrm{X}$-ray, laser scanning, and transmission electron microscopy mapping of the exopolymeric matrix of microbial biofilms", Appl. Environ. Microbiol. 69(9), 5543 (2003). https://doi. org/10.1128/AEM.69.9.5543-5554.2003

14. K. Benzerara, T.H. Yoon, T. Tyliszczak, B. Constantz, A.M. Spormann and G.E. Brown, "Scanning transmission X-ray microscopy study of microbial calcification", Geobiology 2(4), 249 (2004). https://doi. org/10.1111/j.1472-4677.2004.00039.x

15. G.D. Cody, J. Brandes, C. Jacobsen and S. Wirick, "Soft X-ray induced chemical modification of polysaccharides in vascular plant cell walls", J. Electron Spectrosc. Relat. Phenom. 170(1-3), 57-64 (2009). https://doi.org/10.1016/j.elspec.2008.09.007

16. J. Sedlmair, S.-C. Gleber, S.Ö. Mert, M. Bertilson, O. von Hofsten, J. Thieme and T. Pfohl, "Imaging of vascular smooth muscle cells with soft X-ray spectromicroscopy", Microsc. Microanal. 17(6), 991 (2011). https://doi.org/10.1017/S1431927611012165

17. C. Karunakaran, C.R. Christensen, C. Gaillard, R. Lahlali, L.M. Blair, V. Perumal, S.S. Miller and A.P. Hitchcock, "Introduction of soft X-ray spectromicroscopy as an advanced technique for plant biopolymers research", PLOS ONE 10(3), e0122959 (2015). https://doi.org/10.1371/journal.pone.0122959

18. N.D. Telling, J. Everett, J.F. Collingwood, J. Dobson, G. van der Laan, J.J. Gallagher, J. Wang and A.P. Hitchcock, "Iron biochemistry is correlated with amyloid plaque morphology in an established mouse model of Alzheimer's disease", Cell Chem. Biol. 24(10), 1205 (2017). https://doi.org/10.1016/j.chembiol.2017.07.014

19. M. Gayral, K. Elmorjani, M. Dalgalarrondo, S.M. Balzergue, S. Pateyron, M.-H. Morel, S. Brunet,
L. Linossier, C. Delluc, B. Bakan and D. Marion, "Responses to hypoxia and endoplasmic reticulum stress discriminate the development of vitreous and floury endosperms of conventional maize (Zea mays) inbred lines", Front. Plant Sci. 8, 557 (2017). https:// doi.org/10.3389/fpls.2017.00557

20. R. Belkhou, S. Stanescu, S. Swaraj, A. Besson, M. Ledoux, M. Hajlaoui and D. Dalle, "HERMES: a soft X-ray beamline dedicated to X-ray microscopy", J. Synchrotron Radiat. 22(4), 968 (2015). https://doi. org/10.1107/S1600577515007778

21. S. Swaraj, R. Belkhou, S. Stanescu, M. Rioult, A. Besson and A.P. Hitchcock, "Performance of the HERMES beamline at the carbon K-edge", J. Phys. Conf. Ser. 849(1), 012046 (2017). https://doi. org/10.1088/1742-6596/849/1/012046

22. B. Watts, S. Swaraj, D. Nordlund, J. Lüning and H. Ade, "Calibrated NEXAFS spectra of common conjugated polymers", J. Chem. Phys. 134(2), 024702 (2011). https://doi.org/10.1063/1.3506636

23. A.P. Hitchcock, "Soft X-ray spectromicroscopy of polymers and bipolymer interfaces", J. Synchrotron Radiat. 8(Pt 2), 66 (2001). https://doi.org/10.1107/ S0909049500016447

24. M. Lerotic, R. Mak, S. Wirick, F. Meirer and C. Jacobsen, "MANTiS: a program for the analysis of X-ray spectromicroscopy data", J. Synchrotron Radiat. 21(5), 1206 (2014). https://doi.org/10.1107/ S1600577514013964

25. M. Lerotic, C. Jacobsen, T. Schäfer and S. Vogt, "Cluster analysis in soft X-ray spectromicroscopy", Ultramicroscopy (100), 35 (2004). https://doi. org/10.1016/j.ultramic.2004.01.008

26. J. Schindelin, I. Arganda-Carreras, E. Frise, V. Kaynig, M. Longair, T. Pietzsch, S. Preibisch, C. Rueden, S. Saalfeld, B. Schmid, J.-Y. Tinevez, D.J. White, V. Hartenstein, K. Eliceiri, P. Tomancak and A. Cardona, "Fiji: an open-source platform for biological-image analysis", Nat. Methods 9(7), 676 (2012). https://doi. org/10.1038/nmeth.2019 